\title{
BMJ Open Hospital-based acute care in the last 30 days of life among patients with chronic disease that received early, late or no specialist palliative care: a retrospective cohort study of eight chronic disease groups
}

\author{
Madalene Earp (D) , ${ }^{1}$ Pin Cai, ${ }^{2}$ Andrew Fong, ${ }^{3}$ Kelly Blacklaws, ${ }^{3}$ \\ Truong-Minh Pham, ${ }^{4}$ Lorraine Shack, ${ }^{4}$ Aynharan Sinnarajah (D) ${ }^{1,5}$
}

To cite: Earp M, Cai P, Fong A, et al. Hospital-based acute care in the last 30 days of life among patients with chronic disease that received early, late or no specialist palliative care: a retrospective cohort study of eight chronic disease groups. BMJ Open 2021;11:e044196. doi:10.1136/ bmjopen-2020-044196

- Prepublication history and supplemental material for this paper is available online. To view these files, please visit the journal online (http://dx.doi. org/10.1136/bmjopen-2020044196).

Received 25 August 2020 Revised 27 January 2021 Accepted 15 February 2021

Check for updates

(c) Author(s) (or their employer(s)) 2021. Re-use permitted under CC BY-NC. No commercial re-use. See rights and permissions. Published by BMJ.

For numbered affiliations see end of article.

Correspondence to Dr Aynharan Sinnarajah; asinnara@ucalgary.ca

\section{ABSTRACT}

Objective For eight chronic diseases, evaluate the association of specialist palliative care (PC) exposure and timing with hospital-based acute care in the last 30 days of life.

Design Retrospective cohort study using administrative data.

Setting Alberta, Canada between 2007 and 2016.

Participants 47169 adults deceased from: (1) cancer, (2) heart disease, (3) dementia, (4) stroke, (5) chronic lower respiratory disease (chronic obstructive pulmonary disease (COPD)), (6) liver disease, (7) neurodegenerative disease and (8) renovascular disease.

Main outcome measures The proportion of decedents who experienced high hospital-based acute care in the last 30 days of life, indicated by $\geq$ two emergency department (ED) visit, $\geq$ two hospital admissions, $\geq 14$ days of hospitalisation, any intensive care unit (ICU) admission, or death in hospital. Relative risk (RR) and risk difference (RD) of hospital-based acute care given early specialist $P C$ exposure ( $\geq 90$ days before death), adjusted for patient characteristics.

Results In an analysis of all decedents, early specialist PC exposure was associated with a $32 \%$ reduction in risk of any hospital-based acute care as compared with those with no PC exposure (RR 0.69, 95\% Cl 0.66 to 0.71 ; RD $0.16,95 \% \mathrm{Cl} 0.15$ to 0.17$)$. The association was strongest in cancer-specific analyses (RR $0.53,95 \% \mathrm{Cl} 0.50$ to 0.55 ; $\mathrm{RD} 0.31,95 \% \mathrm{Cl} 0.29$ to 0.33 ) and renal disease-specific analyses (RR $0.60,95 \% \mathrm{Cl} 0.43$ to 0.84 ; RD $0.22,95 \% \mathrm{Cl}$ 0.11 to 0.34 ), but a $25 \%$ risk reduction was observed for each of heart disease, COPD, neurodegenerative diseases and stroke. Early specialist PC exposure was associated with reducing risk of four out of five individual indicators of high hospital-based acute care in the last 30 days of life, including $\geq$ two ED visit, $\geq$ two hospital admission, any ICU admission and death in hospital.

Conclusions Early specialist PC exposure reduced the risk of hospital-based acute care in the last 30 days of life for all chronic disease groups except dementia.

\section{Strengths and limitations of this study}

- A strength is the separate analysis of eight different common chronic disease groups.

- Large population-based cohort from a jurisdiction with a well-established specialist palliative care programme operating in institutions and the community.

- Strength is the comprehensive assessment of all specialist palliative care providers (physician, nurses, and allied healthcare professionals) activities in all settings.

- Limitation is that the contribution of non-specialist palliative care providers (eg, family physician) is not included.

- Caution is needed when generalising results to other jurisdictions, particularly those that do not have a well-developed specialist palliative care programme.

\section{INTRODUCTION}

Palliative care $(\mathrm{PC})$ is a key ingredient to providing the best possible care for many patients nearing the end-of-life (EOL). ${ }^{1}$ The WHO defines PC as 'an approach that improves the quality of life (QoL) of patients and their families facing the problems associated with life-threatening illness, through the prevention and relief of suffering by means of early identification and impeccable assessment and treatment of pain and other problems, physical, psychosocial and spiritual'.? Thus, PC focusses on addressing patients' unmet needs around illness comprehension and coping, advanced care planning and decision-making, symptoms and daily functioning, and coordination of care.

In the past, $\mathrm{PC}$ has been provided predominantly to patients with terminal cancer, in large part because the disease trajectory is 
easier to predict. ${ }^{34}$ However, timely access to $\mathrm{PC}$ has been associated with improved QoL for patients with a myriad of chronic diseases. ${ }^{5-9}$ Conditions now considered appropriate for PC include malignant cancer, heart disease, dementia, stroke, chronic lower respiratory disease (chronic obstructive pulmonary disease (COPD)), advanced liver disease, neurodegenerative diseases and renovascular diseases. ${ }^{10}{ }^{11}$ In addition to improving QoL, PC use has been associated with reduced or neutral healthcare cost through reductions in acute care use, for example, emergency department (ED) visits and hospital and intensive care unit admissions (ICU), near the EOL. ${ }^{312-14}$ Thus, greater use of PC has the potential to be a 'win-win' for patients and administrators of health systems.

Many studies have reported on the relationship between PC exposure and healthcare resource use near the EOL for patients with cancer, ${ }^{15-21}$ consistently finding that PC exposure reduces risk of hospital-based care near the EOL. Recently, the same was found to be true for patients with many of the most common chronic diseases; however, questions remain about the role of PC timing on these outcomes. ${ }^{22}$ To address this, for eight chronic diseases, we evaluate the impact of specialist PC timing (early, $\geq 90$ days before death; late, $\geq 8$ but $<90$ days before death; very late, $\leq 7$ days before death; and never) on hospital-based healthcare resource use (ED visits, hospital and ICU admissions, death in hospital) in the 30 days prior to death.

\section{METHODS}

\section{Setting and design}

This study was set in the Calgary Zone (CZ) of Alberta Health Services (AHS). CZ encompasses the city of Calgary and surrounding semirural areas $(88 \%$ urban, $12 \%$ rural). It contains $\sim 1.6$ million people, or $\sim 38 \%$ of Alberta, Canada's population. ${ }^{23}$ AHS is the provincial health authority tasked with delivering publicly funded universal healthcare to the population, including access to $\mathrm{PC}$ in institutional and community settings. The specialist PC service in CZ is a longstanding ( 20 years), mature, integrated programme which includes PC consult teams (institutional, community-based and cancer pain and symptom clinic), a tertiary PC unit, palliative home care (PHC) (available within Calgary city limits only), and hospices (institutional and community-based). ${ }^{24}$ All services provided by and activities performed by the CZ specialist PC programme/providers are captured in operational databases (Sunrise Clinical Manager, Palliative Care Database (PallD), PARIS, and Pathways Continuing Care Application Data, see online supplemental table 1) managed by AHS, which are used to manage workflows, admission, consultation and discharge. The criteria for PC referral in Alberta are like most PC programmes with a focus on symptoms, advance care planning, and general support for patients, caregivers and providers.

\section{Cohort description}

This was an administrative data-based retrospective cohort study of CZ decedents who died between 1 January 2007 and 31 December 2016. Regional, provincial, and national healthcare databases were used to identify palliative, community and acute care service use before death. A list of the databases accessed (including the specialist PC databases), and the information extracted from each, is available (see online supplemental table 1). Patients 18 years or older and deceased from a PC-amenable condition, including: (1) malignant cancer, (2) heart disease and heart failure (abbreviated 'heart disease/failure'), (3) dementia, vascular dementia, Alzheimer's disease, senility (abbreviated 'dementia'), (4) haemorrhagic, ischaemic and unspecified stroke (abbreviated 'stroke'), (5) COPD and respiratory failure (abbreviated 'COPD'), (6) liver disease, (7) neurodegenerative diseases and (8) renovascular disease and renal failure (abbreviated 'renal disease/failure'), were included. ${ }^{10}{ }^{11}$ These conditions were identified based on International Classification of Diseases 10th Revision (ICD-10) codes for underlying cause of death as recorded on the death certificate (see online supplemental table 2 for the ICD-10 codes used). ${ }^{10} 11$ Administrative data were linked, aggregated and deidentified by the data analytics service within AHS.

\section{Patient and public involvement}

All patients were deceased, precluding involvement in the design, conduct, reporting or dissemination plans of our research. The public were not involved in the design, conduct, reporting or dissemination of this research.

The results of this study will be disseminated to the academic community through presentation of the findings at relevant national and international meetings (eg, the annual International Congress on Palliative Care, European Association for Palliative Care, and Canadian Hospice Palliative Care Conference); presenting the findings at local rounds (Tom Baker Cancer Centre, Cumming School of Medicine), and disseminating the results to networks of researchers associated with primary care, palliative care, and health services research (including the O'Brien Institute for Public Health). Strategies to disseminate the findings to healthcare organisations and policy-makers include presenting the study findings to policy makers at the local, provincial (eg, Alberta Health Services, Alberta Health, Covenant Health, Cancer Control Alberta), and national levels.

\section{Outcomes}

The outcomes were the number of decedents with high hospital-based acute care use in the last 30 days of life. Five indicators of this were defined: (1) death in an acute care hospital, (2) two or more ED visit, (3) two or more hospital admissions, (4) 15 or more days of hospitalisation, and (5) any ICU admission. An aggregate indicator (primary outcome) was constructed as: any individual indicators found to occur versus none. This study reports relative risk (RR) and risk difference (RD) of these 
indicator outcomes given specialist PC exposure and timing, adjusting for covariates.

\section{Exposure of interest}

The exposure of interest was specialist PC use. This was categorised as: no specialist PC use (reference category), early specialist $\mathrm{PC}$ occurring $\geq 90$ days before death, late specialist PC occurring $\geq 8$ but $<90$ days before death, and very late specialist PC occurring $<8$ days before death. Unlike previous reports that excluded patients with very late $\mathrm{PC},{ }^{22}$ we chose to included these patients (modelled as a separate group) as we were interested in evaluating associations with our outcome and covariates. PC timing cut-offs (ie, $\geq 8$ and $<90$ days) were selected based on prior research into PC timing and healthcare resource use. $^{1525-27}$

In secondary analyses examining only decedents that received specialist $\mathrm{PC}$, the exposure of interest was categorised as: late specialist PC occurring $\geq 8$ but $<90$ days before death (reference category) versus early specialist $\mathrm{PC}$ occurring $\geq 90$ days before death.

\section{Covariates}

Our statistical analyses controlled for covariates previously shown to be associated with either hospital-based acute care use in the last 30 days of life or specialist PC use. These included underlying chronic disease causing death (categories: cancer (reference), heart disease/ failure, dementia, stroke, COPD, liver disease, neurodegenerative diseases, renal disease/failure), sex (categories: female (reference), male), age at death (categories: $<61,61-70,71-80,81-90$ (reference), $\geq 91$ years old), year of death (categories: 2007-2008 (reference), 2009-2010, 2011-2012, 2013-2014, 2015-2016), rurality of primary residence (categories: urban (reference), rural), Charlson Comorbidity Index (CCI) score adjusted for underlying cause of disease (categories: 0 (reference), $1-2, \geq 3$ ), estimated household income based on postal code (categories: US $\$ 0-71,680$ (reference), US $\$ 71$ 765-90 112, US $\$ 90$ 197-108 032, US\$108 083-128384, US\$128 512-519168 per year), days spent in hospital in the $90-365$ days before death (categories: 0 (reference), 1-10, 11-275), general home care visits before death (categories: 0 (reference)), $\geq 1$ ), and admissions to long-term care before death (categories: 0 (reference), $\geq 1$ ). For rurality, decedents were assigned an urban or rural designation using a 7-level categorisation based on postal code. ${ }^{28}$ The 'urban' designation included the levels: metro, moderate metro influence, and urban; the 'rural' designation included all other levels. An overall (longitudinal) CCI score was calculated for each decedent by collapsing all records of inpatient care from 2002 until death. ${ }^{29}$ CCI scores were calculated using published methodology, ${ }^{30}$ with ICD-10 codes for decedents underlying cause of death removed. Median household income quintiles were derived using 2016 Statistics Canada Dissemination Area (DA) level data for Alberta. ${ }^{32}$ The population was divided into five groups such that $\sim 20 \%$ of the population was in each group.
Household income quintile was then assigned based on decedents last known residence postal code. Categorisation of days spent in hospital in the 90-365 days before death reflects the quartiles observed among all decedents ( 0 days for quartile 1 and 2 ).

\section{Statistical analysis}

Relative risk

To determine the likelihood of hospital-based acute care in the last 30 days of life being associated with specialist $\mathrm{PC}$, we ran modified Poisson regression models ${ }^{33}$ adjusting for underlying chronic disease causing death, sex, age at death, year of death, rurality, income, CCI score, long-term care admission, general home care use, and days spent in hospital before death. All analyses were performed in R V.4.0.0. The general model formula used was: $\operatorname{glm}(\mathrm{O} \sim \mathrm{E}+$ covariates, family=Poisson $(\operatorname{link}=\log ))$, where ' $\mathrm{O}$ ' is the outcome, one of the indicators of hospital-based acute care in the last 30 days of life (with the levels 'no' (reference), 'yes'), and where ' $E$ ' is the exposure of interest, specialist PC use (with the levels 'no' specialist PC use (reference) vs early specialist PC occurring $\geq 90$ days before death, late specialist PC occurring $\geq 8$ but $<90$ days before death, and very late specialist PC occurring $<8$ days before death in the main analysis, and in secondary analyses late specialist PC (reference) vs early specialist PC). Covariates adjusted for are as listed in the 'covariates' section. Robust standard errors were estimated using the covariance matrix of model parameters, obtained using the vcovHC function implemented in the R package sandwich. ${ }^{34}$ A separate Poisson regression model was run for each of the six outcomes listed in the 'Outcome' section. RRs are reported with 95\% CIs based on robust standard errors.

We additionally ran modified Poisson regression models on our data subset by chronic disease condition (8 subanalyses in total), as it was of interest to determine if the associations between specialist PC and hospitalbased acute care in the last 30 days of life varies by chronic disease.

\section{Absolute RD}

Reporting of $\mathrm{RD}$ is recommended for clinical and epidemiological studies. To report RD's for our outcomes and exposure while adjusting for covariates, both binomial and Poisson models with an identity link function were attempted. Both failed to converge, a known problem. ${ }^{35}$ Given this, RDs were estimated from linear regression models (ie, normal or Gaussian distribution with identity link function), an approach supported by simulationbased assessments of model performance when estimating RD given a binary outcome. ${ }^{35}$ The general model formula used to obtain RD's was: glm $(\mathrm{O} \sim \mathrm{E}+$ covariates, family=gaussian (link=identity)). 'O', 'E', and covariates are as described for RRs. RRs are reported with 95\% CIs based on robust standard errors. 


\section{RESULTS}

\section{Characteristics of decedents}

A total of 47169 decedents were identified during the study period. Cancer was the most common underlying cause of death $(39 \%)$, following by heart disease/failure $(32 \%)$. The dementia, stroke and COPD disease groups each accounted for $11 \%, 7 \%$ and $6 \%$ of deaths, respectively (table 1). The liver and neurodegenerative disease groups each made up $2 \%$ of decedents; renovascular disease/failure $1 \%$. Fifty-one per cent of decedents were women, with women making up a larger percentage of the dementia category $(65 \%)$ and a smaller percentage of the liver disease category (39\%) (online supplemental table 3). Patients with liver disease were on average much younger at death; patients with dementia were older at death. Disease groups were similar in their breakdown by rurality, with $12 \%$ of decedents living in rural areas. Overall, decedents were more likely to be in the lowest household income quintile (eg, Q1: expected 20\%, observed $28 \%$, an excess of $+8 \%$ ) (table 1). Liver disease and COPD decedents were even more likely to fall in the lowest household income quintile (Q1: $34 \%$ and 33\%, respectively) (online supplemental table 3). Most patients $(69 \%)$ had a CCI score of 0 (after excluding underlying cause of death). Liver disease, heart disease/failure and COPD decedents were more likely to have CCI scores $\geq 1$. Nineteen per cent of decedents had a long-term care admission prior to death; however, this varied considerably by disease category. Patients with dementia were most likely be admitted to long-term care $(61 \%)$; patients with cancer and liver disease were the least likely, $4 \%$ and $6 \%$, respectively. Two-thirds of decedents $(68 \%)$ had a home care visit prior to death; $55 \%$ had only non-PHC visits. Over $60 \%$ of the cohort spent 0 days in hospital 90-365 days before death, $15 \%$ spent between 1 and 10 days, and $24 \%$ spent between 11 and 275 days in hospital for this period (table 1 ). The COPD, liver disease and renovascular disease/failure groups were more likely to have more days in hospital 90 to 365 days before death (online supplemental table 3 ).

\section{Specialist PC exposure prior to death}

Overall, $49 \%$ of decedents received one or more specialist PC service prior to death (table 1). Patients with cancer were most exposed $(86 \%)$; patients with heart disease least exposed $(20 \%)$. For the other chronic disease categories, the proportion of PC exposed decedents was: neurodegenerative disease, 48\%; renovascular disease, $47 \%$; liver disease, $44 \%$, COPD and respiratory failure, $38 \%$; stroke, $30 \%$; and dementia, $22 \%$. A higher proportion of patients who received specialist PC were younger at death, lived in urban areas, were from higher income quintiles (Q2-Q5), died in the second half of the study period, and were not admitted to LTC (table 1). From 2007 to 2016, we observed a significant increase in the proportion of decedents exposed to specialist PC, overall, and independently for each disease category except renovascular disease (online supplemental table 4). Overall,
PC exposure increased by $10 \%$, from $43 \%$ of decedents in $2007 / 2008$ (years combined) to $53 \%$ of decedents in 2015/2016 (years combined). The biggest changes occurred for liver disease (+29\%; $26 \%$ to $62 \%$ from 2007 to 2016$)$ and COPD $(+25 \%, 22 \%$ to $46 \%$ from 2007 to 2016).

Regarding the timing of first specialist PC exposure, $16 \%$ of decedents experienced early specialist PC exposure, $24 \%$ had late exposure, and $9 \%$ had very late exposure. Across all decedents, the median number of days from first PC exposure to death was 43 (IQR 12-140). However, timing was highly variable by disease category. The duration was shortest for stroke (median 8 days, IQR 6-143) and liver disease (median 12 days, IQR 4-40) patients, and longest for cancer (median 55 days, IQR 20-148), neurodegenerative disease (median 33 days, IQR 9-214) and COPD (median 32 days, IQR 5-244) patients. The remaining chronic disease groups each had a median PC exposure timing of 18-19 days before death. From 2007-2016, early specialist PC exposure increased by $4.7 \%$, from $14 \%$ of decedents in $2007 / 2008$ (years combined) to $19 \%$ of decedents in 2015/2016 (years combined) (online supplemental table 5). The biggest changes occurred for COPD (+14\%, 7\% to 20\% from 2007 to 2016). Finally, patients first encountered specialist PC primarily through PC consult team visits $(81 \%)$, followed by PHC $(15 \%)$ (table 1$)$.

\section{Death in hospital and hospital-based acute care in the last $\mathbf{3 0}$ days of life}

Overall, $42 \%$ of decedents died in an acute care hospital or bed (table 2). Twenty-one per cent of decedents spent $>14$ days in hospital in last 30 days of life. Fewer than $10 \%$ of patients experience the remaining indicators of hospital-based acute care: $>1 \mathrm{ED}$ visit in last 30 days in last 30 days of life $(9 \%)$, $>1$ hospital admission in last 30 days in last 30 days of life $(8 \%)$, and any ICU admission care in last 30 days of life (7\%). Overall, $48 \%$ of decedents experienced one or more indicators of hospital-based acute care. The average number of positive indicators per patient was 1.8 (of 5). Patients with liver disease were notable in being much more likely to experience hospital-based acute care in the last 30 days of life $(78 \%$ of all liver patients); a greater proportion died in hospital $(76 \%)$ and used the ICU (26\%). Patients with dementia were least likely to experience hospital-based acute care $(25 \%)$, and least likely to die in hospital $(20 \%)$.

Over the studied years, there was a significant linear decrease in the proportion of decedents who died in hospital (-2.9\%), spent $\geq 14$ days in hospital in the last 30 days of life $(-2.0 \%)$ or were admitted to the ICU $(-1.3 \%)$ in the last 30 days of life. However, there was a linear increase in the proportion of decedents with $>1$ hospitalisation $(+0.5 \%)$ and $>1 \mathrm{ED}$ visit $(+0.8 \%)$ in the last 30 days of life (online supplemental table 6). Combining these indicators in the aggregate hospital-based acute care indicator, changes over time were not significant. 
Table 1 Summary characteristics of decedents at the time of death

Specialist PC prior to death, $\mathbf{n}$ (row \%)

\begin{tabular}{|c|c|c|c|c|c|c|}
\hline & \multirow[b]{3}{*}{$\begin{array}{l}\text { Overall } \\
\text { (n=47 169), } \\
n(\text { col \%) }\end{array}$} & \\
\hline & & \multirow[b]{2}{*}{$\begin{array}{l}\text { No } \\
(n=23931 \\
(51))\end{array}$} & \multirow[b]{2}{*}{$\begin{array}{l}\text { Yes } \\
(n=23238 \\
(49))\end{array}$} & \multicolumn{3}{|c|}{ Yes, by timing categories* } \\
\hline & & & & $\begin{array}{l}\text { Early ( } \geq 90 \\
\text { before death), } \\
n=7736(33)\end{array}$ & $\begin{array}{l}\text { Late } \\
\text { ( } \geq 8 \text { but< }<90 \text { days } \\
\text { before death), } \\
n=11373(49)\end{array}$ & $\begin{array}{l}\text { Very late } \\
\text { (<8 days } \\
\text { before death), } \\
n=4129(18)\end{array}$ \\
\hline \multicolumn{7}{|l|}{ Chronic disease causing death } \\
\hline Cancer & $18263(39)$ & $2469(14)$ & $15794(86)$ & $5743(36)$ & $8401(53)$ & $1650(10)$ \\
\hline Heart disease/failure & $15206(32)$ & $12165(80)$ & 3041 (20) & $803(26)$ & $1257(41)$ & $981(32)$ \\
\hline Dementia & $5010(11)$ & $3912(78)$ & $1098(22)$ & $321(29)$ & $457(42)$ & $320(29)$ \\
\hline Stroke & $3108(7)$ & $2166(70)$ & $942(30)$ & $121(13)$ & $353(37)$ & $468(50)$ \\
\hline COPD & $2905(6)$ & $1787(62)$ & $1118(38)$ & $426(38)$ & $350(31)$ & $342(31)$ \\
\hline Liver disease & $1044(2)$ & $583(56)$ & $461(44)$ & $60(13)$ & $218(47)$ & $183(40)$ \\
\hline Neurodegenerative disease & $1015(2)$ & $523(52)$ & $492(48)$ & $191(39)$ & $202(41)$ & $99(20)$ \\
\hline Renovascular disease/failure & $618(1)$ & $326(53)$ & $292(47)$ & $71(24)$ & $135(46)$ & $86(29)$ \\
\hline \multicolumn{7}{|l|}{ Sex } \\
\hline Female & $23865(51)$ & $12025(50)$ & $11840(50)$ & 4137 (35) & $5647(48)$ & $2056(17)$ \\
\hline Male & $23304(49)$ & $11906(51)$ & $11398(49)$ & 3599 (32) & $5726(50)$ & $2073(18)$ \\
\hline \multicolumn{7}{|l|}{ Age at death } \\
\hline$<61$ & 6749 (14) & $2672(40)$ & $4077(60)$ & $1699(42)$ & $1914(47)$ & $464(11)$ \\
\hline $61-70$ & 7066 (15) & $2806(40)$ & $4260(60)$ & $1591(37)$ & $2110(50)$ & $559(13)$ \\
\hline $71-80$ & $10449(22)$ & $4658(45)$ & $5791(55)$ & 1838 (32) & 2988 (52) & $965(17)$ \\
\hline $81-90$ & $15355(33)$ & $8573(56)$ & $6782(44)$ & 1957 (29) & 3294 (49) & $1531(23)$ \\
\hline$\geq 91$ & 7550 (16) & $5222(69)$ & $2328(31)$ & $651(28)$ & $1067(46)$ & $610(26)$ \\
\hline \multicolumn{7}{|l|}{ Rurality } \\
\hline Urban & $41664(88)$ & $20352(49)$ & $21312(51)$ & 7171 (34) & $10353(49)$ & 3788 (18) \\
\hline Rural & 5505 (12) & 3579 (65) & 1926 (35) & $565(29)$ & $1020(53)$ & $341(18)$ \\
\hline \multicolumn{7}{|l|}{ Household income quintile } \\
\hline Q1 & $13211(28)$ & 7603 (58) & $5608(42)$ & $1821(32)$ & $2738(49)$ & 1049 (19) \\
\hline Q2 & $10972(23)$ & $5371(49)$ & $5601(51)$ & 1868 (33) & $2776(50)$ & 957 (17) \\
\hline Q3 & 8896 (19) & 4324 (49) & 4572 (51) & 1493 (33) & 2253 (49) & $826(18)$ \\
\hline Q4 & 6614 (14) & 3099 (47) & 3515 (53) & 1125 (32) & 1734 (49) & 656 (19) \\
\hline Q5 & 7476 (16) & 3534 (47) & 3942 (53) & 1429 (36) & $1872(47)$ & $641(16)$ \\
\hline \multicolumn{7}{|l|}{$\mathrm{CCl}$ score } \\
\hline 0 & 32666 (69) & $16787(51)$ & $15879(49)$ & $5720(36)$ & 7857 (49) & 2302 (14) \\
\hline 1 (score 1-2) & $9399(20)$ & $4512(48)$ & $4887(52)$ & $1336(27)$ & $2392(49)$ & $1159(24)$ \\
\hline 2 (score $\geq 3$ ) & $5104(11)$ & 2632 (52) & 2472 (48) & $680(28)$ & 1124 (45) & $668(27)$ \\
\hline \multicolumn{7}{|l|}{ Year of death } \\
\hline 2007-2008 & 8771 (19) & $5043(57)$ & 3728 (43) & 1204 (32) & $1916(51)$ & $608(16)$ \\
\hline 2009-2010 & 9032 (19) & 4795 (53) & $4237(47)$ & 1347 (32) & 2193 (52) & $697(16)$ \\
\hline 2011-2012 & 9195 (19) & 4490 (49) & 4705 (51) & $1600(34)$ & $2259(48)$ & $846(18)$ \\
\hline 2013-2014 & $9731(21)$ & $4673(48)$ & $5058(52)$ & $1663(33)$ & 2425 (48) & 970 (19) \\
\hline 2015-2016 & $10440(22)$ & $4930(47)$ & $5510(53)$ & 1922 (35) & $2580(47)$ & 1008 (18) \\
\hline \multicolumn{7}{|l|}{ Community care use $\dagger$} \\
\hline LTC admission, yes & 8747 (19) & 6419 (73) & $2328(27)$ & $1120(48)$ & $709(30)$ & $499(21)$ \\
\hline Home care visit, yes & $32265(68)$ & $13171(41)$ & $19094(59)$ & $7184(38)$ & $9152(48)$ & $2758(14)$ \\
\hline Non-palliative home care only & $25943(55)$ & $13171(51)$ & $12782(49)$ & $3968(31)$ & $6195(48)$ & $2619(20)$ \\
\hline
\end{tabular}

Continued 
Table 1 Continued

Specialist PC prior to death, $\mathrm{n}$ (row \%)

Yes, by timing categories*

\begin{tabular}{llllll}
$\begin{array}{l}\text { Overall } \\
(n=47169),\end{array}$ & $\begin{array}{l}\text { No } \\
(n=23931\end{array}$ & $\begin{array}{l}\text { Yes } \\
(n=23238\end{array}$ & $\begin{array}{l}\text { Early }(\geq 90 \\
\text { before death), } \\
n=7736(33)\end{array}$ & $\begin{array}{l}\text { Late } \\
(\geq 8 \text { but }<90 \text { days } \\
\text { before death), } \\
n=11373(49)\end{array}$ & $\begin{array}{l}\text { Very late } \\
(<8 \text { days } \\
\text { before death), } \\
n=4129(18)\end{array}$ \\
\hline$(51))$ & $(49))$ & $n=1136$
\end{tabular}

Hospital days $90-365$ days before death

\begin{tabular}{lcccccc} 
Odays & $28562(61)$ & $16717(59)$ & $11845(41)$ & $2504(21)$ & $6747(57)$ & $2594(22)$ \\
1-10 days & $7255(15)$ & $2724(38)$ & $4531(62)$ & $1640(36)$ & $2230(49)$ & $661(15)$ \\
11-275 days & $11352(24)$ & $4490(40)$ & $6862(60)$ & $3592(52)$ & $2396(35)$ & $874(13)$ \\
Initiating specialist PC service & & & & & & \\
Consult team & $18915(40)$ & - & $18915(81) \S$ & $5472(29)$ & $9443(50)$ & $4000(21)$ \\
Inpatient & $13402(71)$ & - & $13402(71) \ddagger$ & $3204(59) \ddagger$ & $6882(73) \ddagger$ & $3316(83) \ddagger$ \\
Community & $5355(28)$ & - & $5355(28) \ddagger$ & $2232(41) \ddagger$ & $2491(26) \ddagger$ & $632(16) \ddagger$ \\
Emergency department & $158(1)$ & - & $158(1) \ddagger$ & $36(1) \ddagger$ & $70(1) \ddagger$ & $52(1) \ddagger$ \\
TPCU & $116(<1)$ & - & $116(0) \S$ & $32(28)$ & $72(62)$ & $12(10)$ \\
Pain and symptom clinic & $638(1)$ & - & $638(3) \S$ & $469(74)$ & $163(26)$ & $6(1)$ \\
Palliative home care & $3568(8)$ & - & $3569(15) \S 1763(49)$ & $1695(47)$ & $111(3)$ \\
\hline
\end{tabular}

*Row percentages shown are calculated of those who received specialist PC, unless otherwise indicated.

†Evaluated at any time prior to death.

$\ddagger$ Column percentage are shown, calculated of those who received a consult team visit within specialist PC strata.

$\S$ Column percentage are shown, calculated of those who received any specialist PC.

$\mathrm{CCl}$, Charlson Comorbidity Index; COPD, chronic obstructive pulmonary disease; LTC, long-term care; PC, palliative care; Q, quintile; TPCU,

tertiary PC unit.

Association between specialist PC and indicators of hospitalbased acute care

All decedents

In the analysis of all decedents (table 3), those exposed to early specialist PC had a $31 \%$ reduction in the risk of experiencing any hospital-based acute care (indicators aggregated) as compared with those with no specialist PC (RR $0.69 ; 95 \%$ CI 0.66 to 0.71 ; RD 0.16 ; $95 \%$ CI 0.15 to
0.17) (figure 1, table 3). Early specialist PC exposure was associated with reduced risk for four of five of the individual outcome indicators examined (figure 2, table 3). These included $>1$ ED visit, $>1$ hospital admission, any ICU admission and death in hospital. It was associated with increased risk having spent $>14$ days in hospital in the last 30 days of life. As compared with no specialist PC exposure, late specialist PC exposure was associated

Table 2 Hospital-based acute care use in the last 30 days of life

\begin{tabular}{lllllll}
\hline & \multicolumn{5}{l}{ Hospital-based acute care in the last 30 days of life } \\
\cline { 2 - 7 } & >1ED visit & $\begin{array}{l}\text { >1 hospital } \\
\text { admission }\end{array}$ & $\begin{array}{l}\text { Any ICU } \\
\text { admission }\end{array}$ & $\begin{array}{l}\text { >14 days in } \\
\text { hospital }\end{array}$ & $\begin{array}{l}\text { Death in an acute care } \\
\text { hospital or bed }\end{array}$ & $\begin{array}{l}\text { Indicators } \\
\text { aggregated }\end{array}$ \\
\hline All decedents & $4224(9)$ & $3861(8)$ & $3073(7)$ & $9903(21)$ & $19679(42)$ & $22712(48)$ \\
Cause of death & & & & & & \\
$\quad$ Cancer & $1960(11)$ & $2007(11)$ & $607(3)$ & $4645(25)$ & $7416(41)$ & $9281(51)$ \\
\hline Heart disease, failure & $1162(8)$ & $927(6)$ & $1533(10)$ & $2418(16)$ & $6337(42)$ & $6904(45)$ \\
\hline Dementia, senility & $143(3)$ & $126(3)$ & $16(0)$ & $673(13)$ & $1020(20)$ & $1259(25)$ \\
\hline Stroke & $339(11)$ & $227(7)$ & $312(10)$ & $644(21)$ & $1846(59)$ & $1958(63)$ \\
\hline COPD & $323(11)$ & $298(10)$ & $247(9)$ & $707(24)$ & $1590(55)$ & $1724(59)$ \\
\hline Liver disease & $168(16)$ & $180(17)$ & $271(26)$ & $448(43)$ & $792(76)$ & $811(78)$ \\
\hline Neurodegenerative diseases & $57(6)$ & $46(5)$ & $42(4)$ & $180(18)$ & $367(36)$ & $425(42)$ \\
\hline Renovascular disease, failure & $72(12)$ & $50(8)$ & $45(7)$ & $188(30)$ & $311(50)$ & $350(57)$ \\
\hline
\end{tabular}

COPD, chronic obstructive pulmonary disease; ED, emergency department; ICU, intensive care unit. 


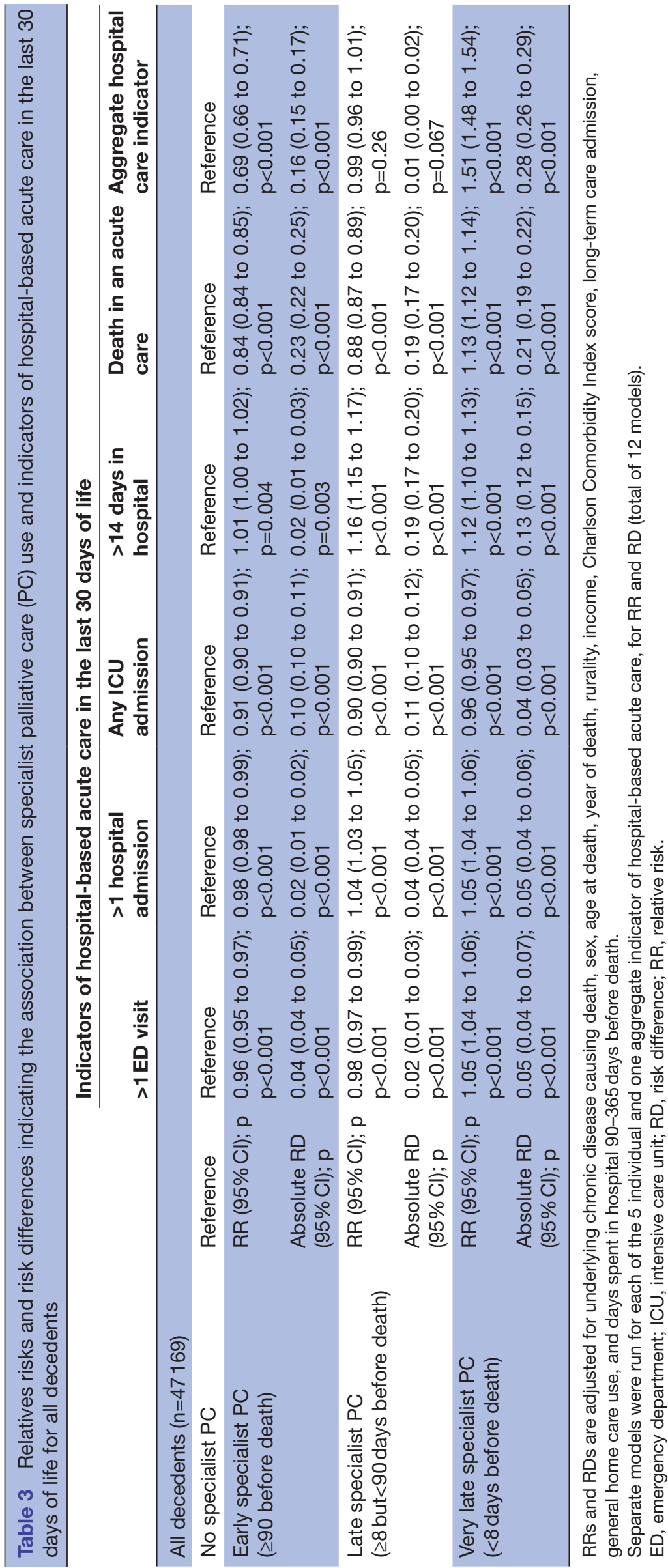




\section{Any indicator of hospital-based acute care in the last 30 days of life (aggregate indicator)}
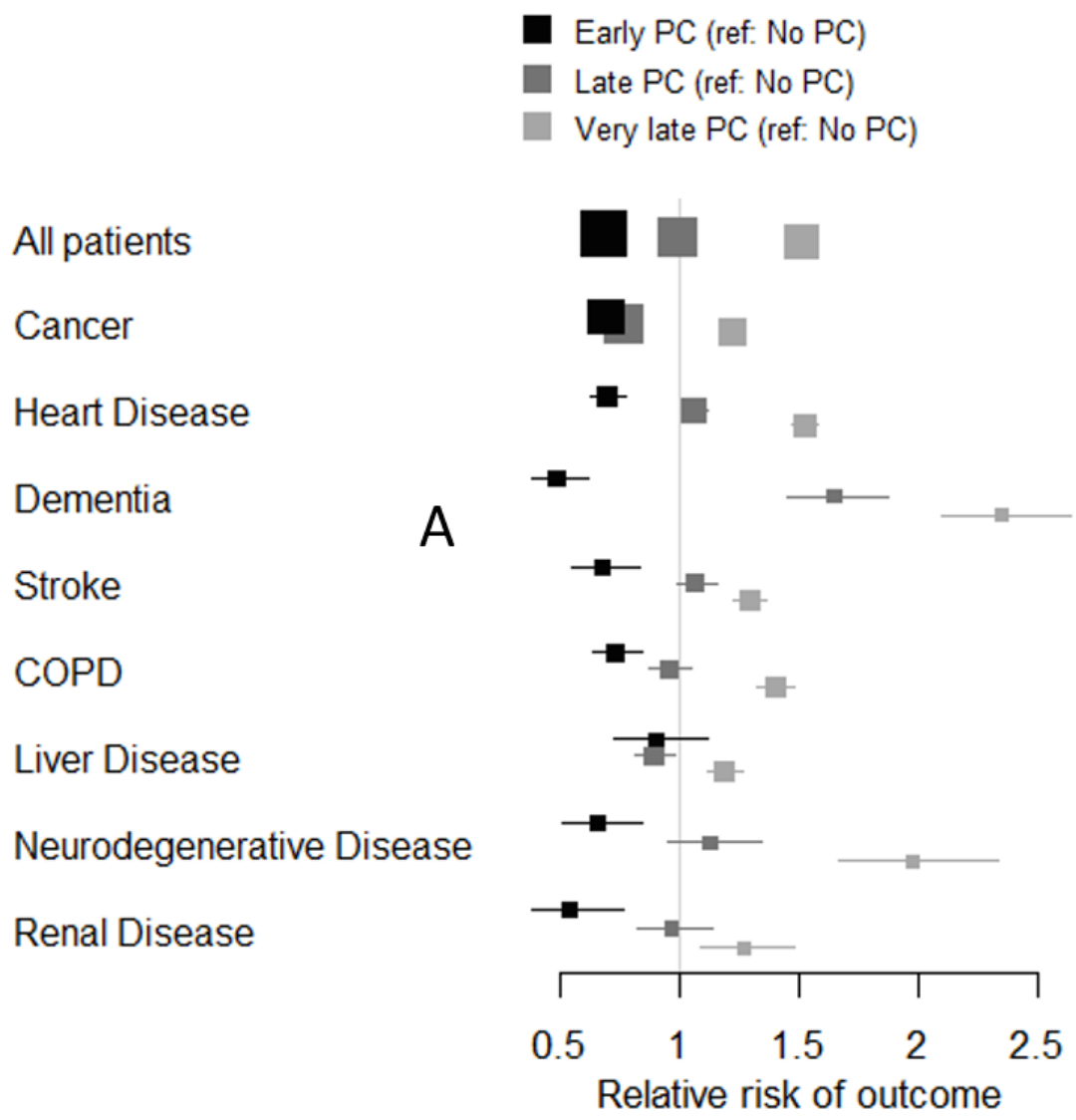

Early PC (ref: Late PC)

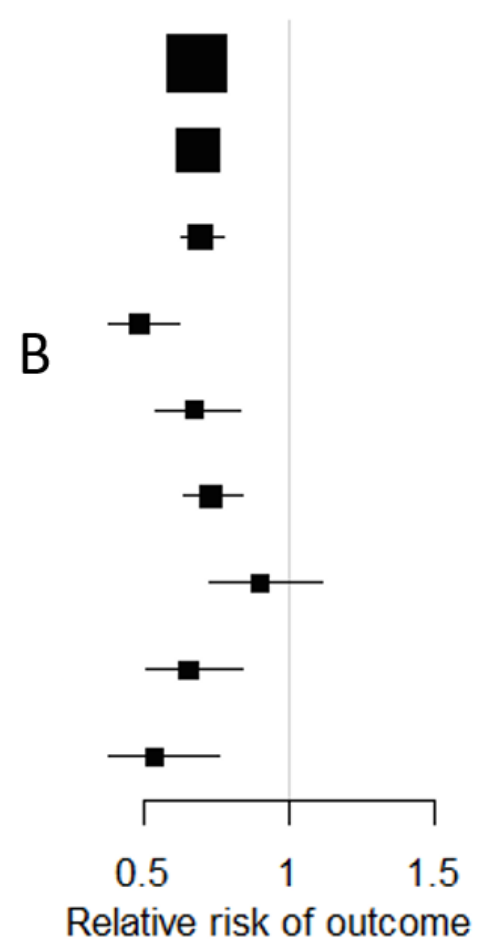

Figure 1 The relative risk (RR) of experiencing any indicator of hospital-based acute care in the last 30 days of life given specialist palliative care (PC) exposure and timing status. In (A) early specialist ( $\geq 90$ days before death), late specialist $P C$ ( $\geq 8$ but $<90$ days before death), and very late specialist PC ( $<8$ days before death), are compared with no specialist PC. In (B), early specialist ( $\geq 90$ days before death) is compared with late specialist $\mathrm{PC}$ ( $\geq 8$ but $<90$ days before death), separating the effect of exposure and timing. Results from eight disease specific and one all decedent model are shown in panels $(A)$ and $(B)(9 \times 2$ total). Exact values of estimates plotted are provided in online supplemental tables 7 and 9). RRs are adjusted for sex, age at death, year of death, rurality, income, Charlson Comorbidity Index score, long-term care admission, general home care use, and days spent in hospital 90-365 days before death. RRs for the all decedent model are also adjusted for chronic disease group. Plots were constructing using the R package forestplot V.1.10. COPD, chronic obstructive pulmonary disease; EOL, end-of-life;.

with reduced risk of ED visits, ICU admission and death in hospital, but increased risk of hospital admission, and spending $>14$ days in hospital (figure 2, table 3). Late PC exposure was not associated with the aggregated outcome (figure 1). As compared with no specialist PC exposure, very late specialist $\mathrm{PC}$ exposure was associated with increased risk for all outcomes except ICU admission, for which it decreased risk.

In a secondary analysis examining only patients that received specialist $\mathrm{PC}$, where early specialist $\mathrm{PC}$ was compared with late specialist PC (figure 1, online supplemental table 7), RR and $\mathrm{RD}$ estimates were found to be similar to main models where early specialist PC was compared with no specialist PC. For example, those exposed to early specialist PC (vs late) had a $32 \%$ reduction in the risk of experiencing any hospital-based acute care (indicators aggregated) (RR $0.68 ; 95 \%$ CI 0.66 to 0.70 ; RD 0.16 ; $95 \%$ CI 0.15 to 0.18 ).

\section{Disease-specific analysis}

For all disease groups except dementia, early specialist PC exposure was associated with reduced risk of any hospitalbased acute care as compared with those who had no PC exposure (figure 1, online supplemental table 8). The effect was strongest in cancer (RR $0.53,95 \%$ CI 0.50 to 0.55 ; RD $0.31,95 \%$ CI 0.29 to 0.33 ) and renal disease (RR $0.60,95 \%$ CI 0.43 to 0.84 ; RD $0.22,95 \%$ CI 0.11 to 0.34 ) decedents, but a $\sim 25 \%$ risk reduction was observed for each of heart disease, COPD, neurodegenerative disease, and stroke. The effect in liver disease patient was smaller but significant (RR 0.81, 95\% CI 0.66 to 0.99). Late specialist PC exposure was associated with reduced risk 


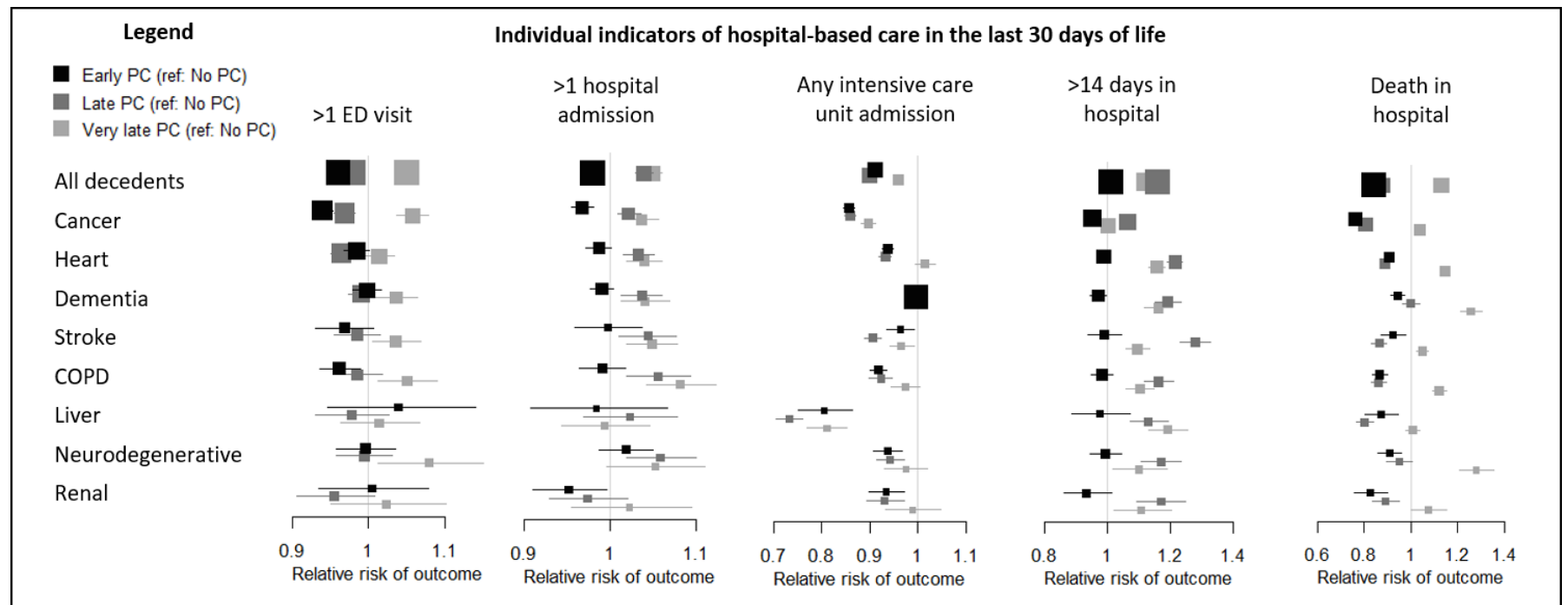

Figure 2 The relative risk (RR) of experiencing individual indicator of hospital-based acute care in the last 30 days of life given specialist palliative care (PC) exposure. Early specialist ( $\geq 90$ days before death), late specialist $P C$ ( $\geq 8$ but $<90$ days before death), and very late specialist PC ( $<8$ days before death), are compared with no specialist PC. Results from eight disease-specific and one all decedent model are shown for each indicator $(8 \times 5$ total). Exact values of estimates plotted are provided in table 3 and online supplemental table 8 . RRs are adjusted for sex, age at death, year of death, rurality, income, Charlson Comorbidity Index score, long-term care admission, general home care use, and days spent in hospital 90-365 days before death. RRs for the all decedent model are also adjusted for chronic disease group. Plots were constructing using the R package forestplot V.1.10. COPD, chronic obstructive pulmonary disease; EOL, end-of-life.

of any hospital-based acute care for patients with cancer (RR $0.76,95 \%$ CI 0.74 to 0.79 ) and liver disease (RR 0.89, $95 \%$ CI 0.81 to 0.98 ), but increased risk for patients with dementia (RR $1.66,95 \%$ CI 1.46 to 1.88 ), and was not associated in the other disease groups (figure 1). Relative to no PC exposure, very late PC exposure was associated with increased risk of any hospital-based acute care for all disease categories. In secondary analyses of only patients that received specialist PC (figure 1 and online supplemental table 9), RR estimates were found to be similar to main models where early specialist PC was compared with no specialist PC.

Of particular interest was death in hospital (inconsistent with most patients preferred location of death) and ICU admission (figure 2). Examining death in hospital alone, early specialist PC exposure reduced risk of this outcome for all disease categories, while late PC exposure significantly reduced risk of death in hospital for all disease categories except dementia and neurodegenerative disease. Examining ICU admission, liver disease is notable in the effect of specialist PC exposure, regardless of timing, on reducing risk of this outcome. In general, ICU admissions are the only hospital-based acute care indicator for which very late specialist PC reduces risk for some disease groups.

\section{DISCUSSION}

\section{Principal findings}

Our analysis of 47169 chronic disease decedents in Calgary, Alberta, Canada from 2007 to 2016 shows that that early specialist PC exposure is associated with reduced risk of hospital-based acute care in the last 30 days of life when compared with those with no specialist PC exposure, or when compared with those with late specialist PC. Four of five outcome indicators showed this relationship (table 3). And, this association was independently observed in all disease groups except for dementia (the latter was not significant). The association between late PC exposure (vs no exposure) was inconsistent across disease groups and outcomes. For most disease categories, late PC exposure was associated with decreased risk of death in hospital and ICU admission, but increased risk of $>1$ hospital admission and $>14$ days in hospital in the last month of life. We hypothesise this result is explained by patients whose first exposure to specialist PC occurs in the last month of life (but $>7$ days), likely triggered by a hospital admission in the last month life. Specialist PC would be highly correlated with hospital admission (ie, increase risk) for these patients. Importantly however, late specialist PC was still associated with reduced risk of ICU admission and death in hospital for these patients. Finally, very late PC (vs no exposure) was consistently associated with increased risk of hospital-based acute care indicators (all except ICU admission) across all disease groups. Specialist PC initiated this late would not be expected to reduce healthcare resources use in the last 30 days of life, nor provide sufficient time to organise the healthcare resources needed to enable death at home. These patients likely only receive specialist PC because they were in hospital in the last 7 days of life, explaining the observed increase in risk. 


\section{Comparison with other studies}

Many studies have reported on the relationship between PC exposure and hospital-based acute care near the EOL in patients with cancer, ${ }^{15-21}$ consistently finding that PC exposure reduces risk of hospital-based care near the EOL. Fewer studies have focused on patients without cancer, and results have been limited to the disease categories examined (heart failure, ${ }^{36-39}$ dementia, ${ }^{40} 41$ end-stage renal disease (ESRD), ${ }^{42} 43$ and end-stage liver $\left.\operatorname{disease}^{44}\right)$. In these prior studies, PC exposure has not been consistently associated with indicators of healthcare resource use (often not significant). However, a recent well-powered study of seven chronic disease, looking at the impact of physician-delivered PC on hospital-based acute care, found results similar to ours. ${ }^{22}$ Indeed, Quinn et al found that PC exposure (any vs none) was associated with reduced rates of ED visits, hospital and ICU admissions, and death in hospital for cancer, COPD, ESRD, stroke and cirrhosis (liver) decedents. ${ }^{22}$ Our study add to these results by showing the association of PC timing on these outcomes. We show that early PC exposure, over late, is associated with reductions in risk of hospital-based acute care in the last 30 days of life. These studies are notably different in how PC is measured. Quinn et al defined PC exposure as newly initiated (in last 6 months of life but excluding the last 7 days), physician delivered, and based on billing data. ${ }^{22}$ Here, $\mathrm{PC}$ is defined as any specialist PC service (physician or nursing consultants, PHC, hospice) at any time (after diagnosis of underlying cause of death), based on data from specialist PC operational databases. Yet, the overall results are similar, with additional clarity now on the association of early versus late PC timing. Similar to our study, Rosenwax et at $t^{45}$ observed increased PC exposure over time for patients without cancer chronic disease in Australia, ${ }^{45}$ as did a recent study of Ontario decedents (2004-2014). ${ }^{46}$ In both, as in our study, the biggest increases occur for patients with liver disease and COPD.

\section{Strengths and limitations}

While this study was large and population based, it had several important limitations. First, the outcome indicators used in this study were developed and validated based on patients with cancer use of healthcare resources. ${ }^{47}$ Indicators specific to non-cancer chronic diseases are not well developed or validated. As a result, the outcomes examined may not be as appropriate for measuring quality of EOL care for the non-cancer chronic diseases categories. Patient and provider preferences for EOL care may differ by chronic disease condition and require further exploration to interpret the associations reported here. Development of disease-specific quality of EOL care indicators would help ensure the right outcomes (those that matter to patients) are used in future research. As it is, not all hospital-based acute care in the last 30 days of life is inappropriate, and we do not mean to imply that healthcare interventions should solely focus on reducing such care. Some hospital-based interventions at the EOL are likely appropriate and in line with patient and caregiver preferences. Unfortunately, data on patient preferences are not available in our healthcare administrative data and is beyond the scope of this study.

Second, unlike prior studies based on billing claims data, 181922 here we only evaluated care provided by specialist PC providers (as recorded in institutional specialist PC databases). As the latter databases are used to manage all day-to-day specialist PC team-patient activities (eg, consultation, admission), there should be very little misclassification in terms of who received specialist PC (and when); however, this has not been formally measured and reported on. Importantly, there is no specialist PC provision outside of this in our jurisdiction. Our PC data sources (listed in online supplemental table 1) and study approach are anticipated to result in underreporting of $\mathrm{PC}$ exposure, specifically as it relates to $\mathrm{PC}$ provided by non-specialist PC providers (eg, generalist physicians). However, our data sources and approach confer high confidence that all specialist PC services received by patients are accurately captured, across all care settings (ie, home, hospital, and hospice).

Finally, this study examined only specialist $\mathrm{PC}$ provided to patients living in a primarily urban region (12\% rural population), in one province, in a high-income country. Caution is needed when generalising to other jurisdictions. In regions that do not have a well-developed specialist PC programme (a programme that is itself a result of the population being studied), patient's PC needs must be met by non-specialist providers or go unmet. The PC delivered by these providers (or alternative programmes) may differ in their effect on the hospital-based outcomes examined here. Even in jurisdiction with well-developed PC programmes, patient preferences for care may differ by population (influenced, for example, by social and cultural factors), and could affect the choice to receive PC and other acute care interventions. We note that our results are largely consistent with those of a recent wellpowered study of patients with chronic disease in Ontario, Canada. $^{22}$

\section{Implications for clinicians and policy-makers}

More work is needed to address differences in PC access observed here and elsewhere. ${ }^{45} 46$ Further, more work is needed to ensure earlier timing of first PC exposure. We know PC benefits patients without cancer chronic disease through QoL improvements. ${ }^{48-50}$ Our current result shows that PC is also associated with reducing risk of hospital-based acute care in the last 30 days of life across most chronic disease categories. Sufficient follow-up time is necessary for the benefits of specialist $\mathrm{PC}$ to be realised; hence, the call for earlier PC, however, late PC is still better than none in terms of reducing death in hospital and ICU admissions. Given finite healthcare resources, chronic disease groups with lower PC exposure and more likely to experience hospital-based acute care in the last 30 days of life, could be prioritised for focused efforts to improve access. For example, $78 \%$ of liver disease and 
$59 \%$ of COPD decedents experience hospital-based acute care in the last 30 days of life, but only $44 \%$ (6\% early) and $38 \%$ ( $15 \%$ early), respectively, receive specialist PC. Patients dying from these conditions still lag far behind patients with cancer both in terms of PC access and timing.

\section{Unanswered questions and future work}

The reality for many jurisdictions is very limited access to, or a continuing lack of, specialist PC providers. Given this, the importance of disease-specific specialists and primary care physicians in providing PC, particularly early $\mathrm{PC}$, and early initiation of advance care planning discussions, cannot be overstated. An ongoing challenge is knowing precisely when and who to refer to specialist PC to best leverage these providers expertise,${ }^{51}$ recognising that in many places this is a scarce resource. This is true particularly for patients without cancer chronic diseases where the disease trajectory is less predictable, and can be much longer. ${ }^{451}$ Addressing this challenge is important as evidence shows that the addition of PC benefits outcomes for patients ${ }^{52}$ with and without cancer. ${ }^{53-55}$ Future work examining differing patient needs and preferences by chronic disease is needed, and could inform referral to specialist PC services, which in turn would impact timing of PC referrals. Development of disease-specific quality of EOL care indicators would help ensure that the right outcomes are focused on by all providers.

Within specialist PC, questions remain on the role that location and model of delivery play in improving patient QoL and optimising healthcare resource use near the EOL. ${ }^{52}$ For example, how do the different specialist PC services (eg, PHC, palliative consult team) compare in their impact on QoL and EOL resource use outcomes, and does it differ by chronic disease (underlying cause of death). At the level of individual specialist PC services, is there a difference in timing for each? For many patients, specialist PC is a complex, multifaceted intervention, and determining what aspect of the care have the greatest impact on outcomes could help in determining how to deliver the highest quality and highest value EOL care.

\section{Author affiliations}

${ }^{1}$ Division of Palliative Medicine, Department of Oncology, Cumming School of Medicine, University of Calgary, Calgary, Alberta, Canada

${ }^{2}$ Clinical Workforce Planning, Alberta Health Services, Calgary, Alberta, Canada

${ }^{3}$ Data \& Analytics, Alberta Health Services, Calgary, Alberta, Canada

${ }^{4}$ Surveillance and Reporting, Cancer Research and Analytics, Cancer Care Alberta,

Alberta Health Services, Calgary, Alberta, Canada

${ }^{5}$ Palliative \& End of Life Care Program, Calgary Zone, Alberta Health Services, Calgary, Alberta, Canada

\section{Twitter Aynharan Sinnarajah @DrASinnarajah}

Contributors ME, AS, PC and AF contributed to the study concept and design. PC, $A F, K B, T-M P$ and $L S$ were responsible for acquisition of data. ME, AF, KB, PC and AS were responsible for data processing and interpretation of the data. ME performed all statistical analyses and drafted the manuscript. AS, PC, AF, KB, T-MP and LS contributed to the critical revision of the manuscript for important intellectual content. AS obtained funding and is the guarantor. The corresponding author attests that all listed authors meet the authorship criteria and that no other authors meeting the criteria have been omitted.
Funding The analysis was supported by a research grant AS received from the MSI Foundations (Grant \#893) to perform this work.

Competing interests All authors have completed the ICMJE uniform disclosure form at www.icmje.org/coi_disclosure.pdf and declare: support from a research grant AS received from the MSI Foundation to perform this work; no financial relationships with any organisations that might have an interest in the submitted work in the previous three years; no other relationships or activities that could appear to have influenced the submitted work.

Patient consent for publication Not required.

Ethics approval Ethics approval was granted by the University of Calgary Human Research Ethics Cancer Committee (17-0445).

Provenance and peer review Not commissioned; externally peer reviewed.

Data availability statement Data are available upon reasonable request. The data set from this study is held securely in coded form at the University of Calgary. While the conditions of our ethics approval prohibit making the data set publicly available, access to anonymised summary level (aggregate data) may be granted (conditional on permission from data custodian: Alberta Health Services) upon request by emailing ayn.sinnarajah@ahs.ca. The full data set creation plan and underlying analytic code are available upon request by emailing ayn.sinnarajah@ahs.ca, understanding that the programmes may rely on coding templates or macros that are unique Alberta Health Services and this study.

Supplemental material This content has been supplied by the author(s). It has not been vetted by BMJ Publishing Group Limited (BMJ) and may not have been peer-reviewed. Any opinions or recommendations discussed are solely those of the author(s) and are not endorsed by BMJ. BMJ disclaims all liability and responsibility arising from any reliance placed on the content. Where the content includes any translated material, BMJ does not warrant the accuracy and reliability of the translations (including but not limited to local regulations, clinical guidelines, terminology, drug names and drug dosages), and is not responsible for any error and/or omissions arising from translation and adaptation or otherwise.

Open access This is an open access article distributed in accordance with the Creative Commons Attribution Non Commercial (CC BY-NC 4.0) license, which permits others to distribute, remix, adapt, build upon this work non-commercially, and license their derivative works on different terms, provided the original work is properly cited, appropriate credit is given, any changes made indicated, and the use is non-commercial. See: http://creativecommons.org/licenses/by-nc/4.0/.

\section{ORCID iDs}

Madalene Earp http://orcid.org/0000-0001-5955-0283

Aynharan Sinnarajah http://orcid.org/0000-0002-7967-159X

\section{REFERENCES}

1 The Way Forward Integration Initiative. The way forward national framework: a roadmap for an integrated palliative approach to care, quality end of life care coalition and CHPCA, 2015. Available: http:// www.hpcintegration.ca/media/60044/TWF-framework-doc-Eng2015-final-April1.pdf

2 World Health Organization. WHO definition of palliative care: World Health Organization, 2015. Available: http://www.who.int/cancer/ palliative/definition/en/

3 Rocker G, Downar J, Morrison RS. Palliative care for chronic illness: driving change. CMAJ 2016;188:E493-8.

4 Lunney JR, Lynn J, Foley DJ, et al. Patterns of functional decline at the end of life. JAMA 2003;289:2387-92.

5 Kavalieratos D, Corbelli J, Zhang D, et al. Association between palliative care and patient and caregiver outcomes: a systematic review and meta-analysis. JAMA 2016;316:2104-14.

6 Diop MS, Rudolph JL, Zimmerman KM, et al. Palliative care interventions for patients with heart failure: a systematic review and meta-analysis. J Palliat Med 2017;20:84-92.

7 Higginson IJ, Bausewein C, Reilly CC, et al. An integrated palliative and respiratory care service for patients with advanced disease and refractory breathlessness: a randomised controlled trial. Lancet Respir Med 2014;2:979-87.

8 Temel JS, Greer JA, Muzikansky A, et al. Early palliative care for patients with metastatic non-small-cell lung cancer. N Engl J Med 2010;363:733-42.

9 Zimmermann C, Swami N, Krzyzanowska M, et al. Early palliative care for patients with advanced cancer: a cluster-randomised controlled trial. Lancet 2014;383:1721-30. 
10 Murtagh FEM, Bausewein C, Verne J, et al. How many people need palliative care? A study developing and comparing methods for population-based estimates. Palliat Med 2014;28:49-58.

11 Rosenwax LK, McNamara B, Blackmore AM, et al. Estimating the size of a potential palliative care population. Palliat Med 2005; 19:556-62.

12 Canadian hospice Palliative care Association. The way forward national framework: cost-effectiveness of palliative care, 2012. Available: http://hpcintegration.ca/media/24434/TWF-Economicsreport-Final.pdf

13 Seow H, Salam-White L, Bainbridge D. Community-based specialist palliative care teams and health system costs at end of life: a retrospective matched cohort study. CMAJ Open 2019;7:E73-80.

14 Qureshi D, Tanuseputro P, Perez R, et al. Early initiation of palliative care is associated with reduced late-life acute-hospital use: a population-based retrospective cohort study. Palliat Med 2019;33:150-9.

15 de Oliveira Valentino TC, Paiva CE, Hui D, et al. Impact of palliative care on quality of end-of-life care among Brazilian patients with advanced cancers. J Pain Symptom Manage 2020;59:39-48.

16 Conlon MSC, Caswell JM, Knight A, et al. Impact of comprehensive hospice palliative care on end-of-life care: a propensity-scorematched retrospective observational study. CMAJ Open 2019;7:E197-202.

17 Seow H, Brazil K, Sussman J, et al. Impact of community based, specialist palliative care teams on hospitalisations and emergency department visits late in life and hospital deaths: a pooled analysis. BMJ 2014;348:g3496.

18 Delisle ME, Ward MAR, Helewa RM, et al. Timing of palliative care in colorectal cancer patients: does it matter? J Surg Res 2019;241:285-93.

19 Triplett DP, LeBrett WG, Bryant AK, et al. Effect of palliative care on aggressiveness of end-of-life care among patients with advanced cancer. J Oncol Pract 2017;13:e760-9.

20 Barbera L, Paszat L, Chartier C. Indicators of poor quality end-of-life cancer care in Ontario. J Palliat Care 2006;22:12-17.

21 Ziegler LE, Craigs CL, West RM, et al. Is palliative care support associated with better quality end-of-life care indicators for patients with advanced cancer? A retrospective cohort study. BMJ Open 2018;8:e018284.

22 Quinn KL, Stukel T, Stall NM, et al. Association between palliative care and healthcare outcomes among adults with terminal noncancer illness: population based matched cohort study. BMJ 2020;370:m2257.

23 Statistics Canada. Census profile, 2016 census. Calgary zone health region, 2017. Available: https://www12.statcan.gc.ca/censusrecensement/2016/dp-pd/prof/details/page.cfm?Lang=E\&Geo1= HR\&Code1=4832\&Geo2=PR\&Code2=48\&SearchText=Calgary\& SearchType $=$ Begins $\&$ SearchPR $=01 \& B 1=$ Population $\& T A B I D=1 \&$ type $=0$

24 Alberta Health Services. Palliative and end of life care: Calgary zone, 2020. Available: https://www.albertahealthservices.ca/info/ Page14778.aspx

25 Scibetta C, Kerr K, Mcguire J, et al. The costs of waiting: implications of the timing of palliative care consultation among a cohort of decedents at a comprehensive cancer center. J Palliat Med 2016;19:69-75.

26 de Oliveira Valentino TC, Paiva BSR, de Oliveira MA, et al. Factors associated with palliative care referral among patients with advanced cancers: a retrospective analysis of a large Brazilian cohort. Support Care Cancer 2018;26:1933-41.

27 Hui D, Kim SH, Roquemore J, et al. Impact of timing and setting of palliative care referral on quality of end-of-life care in cancer patients. Cancer 2014;120:1743-9.

28 Alberta Health Services. Official standard geographic areas, 2018. Available: https://open.alberta.ca/dataset/a14b50c9-94b24024-8ee5-c13fb70abb4a/resource/70fd0f2c-5a7c-45a3-bdaae1b4f4c5d9a4/download/official-standard-geographic-areadocument.pdf

29 Manitoba Centre for Health Policy. Charlson comorbidity: SAS code - calculating a longitudinal charlson comorbidity index score, 2014. Available: http://mchp-appserv.cpe.umanitoba.ca/viewConcept.php? printer $=Y \&$ conceptID=1098

30 Canadian Institute for Health Information. Hospital standardized mortality ratio: technical notes, 2019. Available: https://www.cihi.ca/ sites/default/files/document/hsmr-tech-notes-sept-2019-en-web.pdf

31 Quan H, Li B, Couris CM, et al. Updating and validating the Charlson comorbidity index and score for risk adjustment in hospital discharge Abstracts using data from 6 countries. Am J Epidemiol 2011:173:676-82.

32 Statistics Canada. Dissemination area boundary files, 2016. Available: https://www150.statcan.gc.ca/n1/en/catalogue/92-169-X

33 Zou G. A modified poisson regression approach to prospective studies with binary data. Am J Epidemiol 2004;159:702-6.

34 Zeileis A, Köll S, Graham N. Various Versatile Variances: An ObjectOriented Implementation of Clustered Covariances in R. J Stat Softw 2020;95:1-36.

35 Pedroza C, Truong VT. Performance of models for estimating absolute risk difference in multicenter trials with binary outcome. BMC Med Res Methodol 2016;16:113.

36 Bekelman DB, Allen LA, McBryde CF, et al. Effect of a collaborative care intervention vs usual care on health status of patients with chronic heart failure: the CASA randomized clinical trial. JAMA Intern Med 2018;178:511-9.

37 Brännström M, Boman K. Effects of person-centred and integrated chronic heart failure and palliative home care. prefer: a randomized controlled study. Eur J Heart Fail 2014;16:1142-51.

38 Rogers JG, Patel CB, Mentz RJ, et al. Palliative care in heart failure: the PAL-HF randomized, controlled clinical trial. J Am Coll Cardiol 2017;70:331-41.

39 Sidebottom AC, Jorgenson A, Richards $\mathrm{H}$, et al. Inpatient palliative care for patients with acute heart failure: outcomes from a randomized trial. J Palliat Med 2015;18:134-42.

40 Agar M, Luckett T, Luscombe G, et al. Effects of facilitated family case conferencing for advanced dementia: a cluster randomised clinical trial. PLoS One 2017;12:e0181020.

41 Ahronheim JC, Morrison RS, Morris J, et al. Palliative care in advanced dementia: a randomized controlled trial and descriptive analysis. J Palliat Med 2000;3:265-73.

42 Wong FKY, Ng AYM, Lee PH, et al. Effects of a transitional palliative care model on patients with end-stage heart failure: a randomised controlled trial. Heart 2016;102:1100-8.

43 Chambers $\mathrm{S}$, Healy $\mathrm{H}$, Hoy WE, et al. Health service utilisation during the last year of life: a prospective, longitudinal study of the pathways of patients with chronic kidney disease stages 3-5. BMC Palliat Care 2018;17:57.

44 Patel AA, Walling AM, Ricks-Oddie J, et al. Palliative care and health care utilization for patients with end-stage Liver disease at the end of life. Clin Gastroenterol Hepatol 2017;15:1612-9.

45 Rosenwax L, Spilsbury K, McNamara BA, et al. A retrospective population based cohort study of access to specialist palliative care in the last year of life: who is still missing out a decade on? BMC Palliat Care 2016;15:46.

46 Hill AD, Stukel TA, Fu L, et al. Trends in site of death and health care utilization at the end of life: a population-based cohort study. CMAJ Open 2019;7:E306-15.

47 Earle CC, Park ER, Lai B, et al. Identifying potential indicators of the quality of end-of-life cancer care from administrative data. J Clin Oncol 2003;21:1133-8.

48 Ostgathe C, Alt-Epping B, Golla H, et al. Non-Cancer patients in specialized palliative care in Germany: what are the problems? Palliat Med 2011;25:148-52.

49 Kaasa S, Torvik K, Cherny N, et al. Patient demographics and centre description in European palliative care units. Palliat Med 2007;21:15-22.

50 Stiel S, Heckel M, Seifert A, et al. Comparison of terminally ill cancer- vs. non-cancer patients in specialized palliative home care in Germany - a single service analysis. BMC Palliat Care 2015;14:34

51 Fendler TJ, Swetz KM, Allen LA. Team-Based palliative and end-oflife care for heart failure. Heart Fail Clin 2015;11:479-98.

52 Hui D, Hannon BL, Zimmermann C, et al. Improving patient and caregiver outcomes in oncology: team-based, timely, and targeted palliative care. CA Cancer J Clin 2018;68:356-76.

53 Bakitas MA, Dionne-Odom JN, Ejem DB, et al. Effect of an early palliative care telehealth intervention vs usual care on patients with heart failure: the enable CHF-PC randomized clinical trial. JAMA Intern Med 2020;180:1203-13.

54 Barnes A, Woodman RJ, Kleinig P, et al. Early palliative care referra in patients with end stage liver disease is associated with reduced resource utilisation. J Gastroenterol Hepatol 2019. doi:10.1111/ jgh.14877. [Epub ahead of print: 15 Oct 2019]

55 Baumann AJ, Wheeler DS, James M, et al. Benefit of early palliative care intervention in end-stage liver disease patients awaiting liver transplantation. J Pain Symptom Manage 2015;50:882-6. 